\title{
Original Research Anatomy \\ Correlation between facial types and muscle TMD in women: an anthropometric approach
}

Ronaldo Pacheco de ARAUJO(a) Francisco Carlos GROPPO(b) Luiz Eduardo Nunes FERREIRA(b) Antônio Sérgio GUIMARÃES(a) Sidney Raimundo FIGUEROBA ${ }^{(b)}$

(a) Universidade Federal de São Paulo UNIFESP, College of Medicine, Department of Morphology, São Paulo, SP, Brazil.

(b) University of Campinas - UNICAMP, Piracicaba Dentistry School, Department of Physiological Sciences, Piracicaba, SP, Brazil.

Declaration of Interests: The authors certify that they have no commercial or associative interest that represents a conflict of interest in connection with the manuscript.

Corresponding Author:

Sidney Raimundo Figueroba

E-mail:sfigueroba@uol.com.br

DOI: 10.1590/1807-3107BOR-2015.vol29.0084

Submitted: Nov 13, 2014

Accepted for publication: Mar 10, 2015

Last revision: May 29, 2015
Abstract: Temporomandibular disorders (TMD) affecting the articular disc and/or the facial muscles are common among the population, recording a higher incidence in women age 20-40 years. The aim of this study was to investigate the correlation between facial types and muscle TMD in women. This study comprised 56 women age 18 to 49 years, seeking treatment for TMD at the School of Medicine, Federal University of São Paulo. All of the study individuals were diagnosed with muscle TMD, based on the Research Diagnostic Criteria (RDC). Facial type was determined using the Facial Brugsch Index and classified as euryprosopic (short and/or broad), mesoprosopic (average width) and leptoprosopic (long and/or narrow). The data were submitted to the Chi-square test and ANOVA-Tukey's test to conduct the statistical analysis. The faces of 27 individuals were classified as euryprosopic (48\%), 18 as mesoprosopic (32\%), and 11 as leptoprosopic $(20 \%)$. A statistically significant difference (Chi-square, $p=0.032$ ) was found among the facial types, in that leptoprosopic facial types showed the lowest values for muscle TMD. A greater number $(p=0.0007)$ of cases of muscle TMD were observed in the 20 to 39 year-old subjects than in the subjects of other age segments. In conclusion, women with euryprosopic facial types could be more susceptible to muscle TMD. Further studies are needed to investigate this hypothesis.

Keywords: Temporomandibular Joint Disorders; Facial Pain; Gender and Health; Anatomy; Muscles.

\section{Introduction}

Miscegenation is a worldwide phenomenon and produces different biotypes among humans. Three distinct facial types (euryprosopic, mesoprosopic, and leptoprosopic), as well as extreme variations (brachyfacial and dolichofacial), have been reported in the literature.

Craniometry, the branch of physical anthropology that deals with the study and measurement of skulls, was the first resource used to investigate human body growth. Craniometric reference points are used to determine the variations in skull shape. Cranial dimensions, such as width, length, and height, are used to classify facial types. ${ }^{1}$ Measurement of the head, involving the bones of the cranium and the face of living beings, is called cephalometry. ${ }^{2}$ 
Studies on muscle activity and facial morphology have revealed that people with hypodivergent occlusal and mandibular facial planes are more likely to have rectangular-shaped faces (mesoprosopic) with reduced facial height. These individuals tend to apply greater forces during chewing, and experience clenching phenomena, which could result in orofacial pain. ${ }^{3}$

Individuals with a long facial type (leptoprosopic) have been reported to exert significantly lower forces during both mastication and induced clenching, as compared with individuals with a balanced facial type (mesoprosopic). ${ }^{4}$ Several studies have correlated changes in the TMJ with craniofacial patterns. $5,6,7$

Disorders in the masticatory muscles and TMJ have been associated with facial types and development of facial bones and muscles. . $^{8,910,11}$

The etiology of temporomandibular disorders (TMD) is multifactorial, since it is related to a number of dental and medical conditions, such as dental occlusion, orthodontic treatment, improper tooth restorations, posture, parafunctional habits, genetic and psychosocial factors, emotional stress, trauma, anatomy of the disc, pathophysiology of the muscles, age, and gender. ${ }^{12,13}$

Epidemiological studies have reported women as more susceptible to $\mathrm{TMD}_{1}^{14,15,16,17,18,19}$ with symptom severity associated with patient age. ${ }^{20} \mathrm{~A}$ higher proportion of TMD has been found for women age 20-40 years, than for menopausal women, children, or adolescents. ${ }^{16,21}$

Craniofacial anthropometry is considered a reliable, non-invasive and low-cost method, and should be conducted by a calibrated professional. ${ }^{22}$ In the present study, anthropometric cephalometry was used to classify the patients' facial types, and verify whether they are correlated with muscle TMD.

\section{Methodology}

Of the roughly 1,000 female patients from theSchool of Medicine of the Federal University of São Paulo (Universidade Federal de São Paulo - UNIFESP), 65 were selected according to the inclusion criteria. Fifty-six women age 18 to 49 years ( $\mathrm{SD}= \pm 8.8$ years) participated in this study, which was approved by the Human Research Ethics Committee of the School of Medicine- UNIFESP (protocol: 1084/02). The subjects were selected and diagnosed with muscle TMD, based on the Research Diagnostic Criteria (RDC/TMD). ${ }^{23}$ Written informed consent was provided by all the study individuals.

The craniometrical points used for the face measurements were (a) nasion - the midpoint of the frontonasal suture, (b) gnathion - the most inferior point of the mandible in the midline, and (c) zygion - the most lateral point on the zygomatic arch (Figure 1). Just one previously calibrated operator performed all the measurements with an anthropometric compass, according to a technique described by Farkas et al. ${ }^{24}$ and Allanson. ${ }^{25}$

Measurements were made to obtain the Facial Brugsch Index (FI), which is the ratio (in percentage) of the maximum height (Figure 2) to the maximum width of the face (Figure 3).

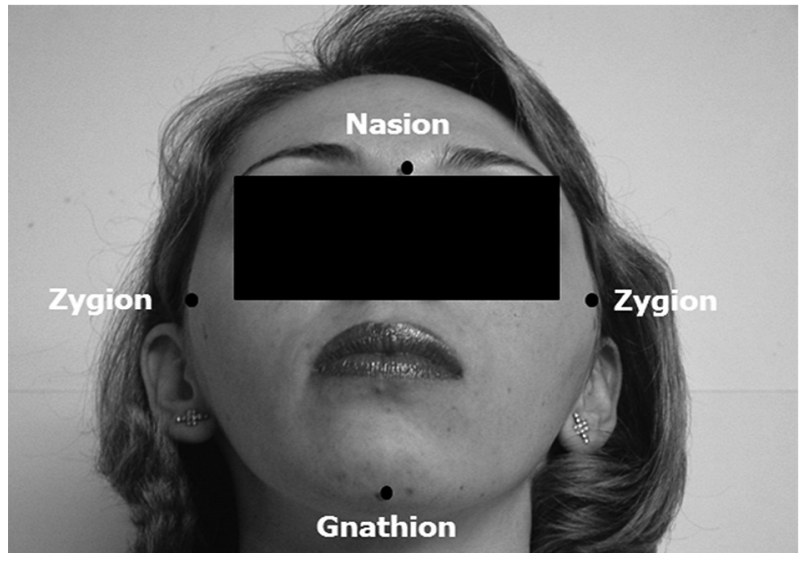

Figure 1. Craniometric points (nasion, gnathion and zygion).

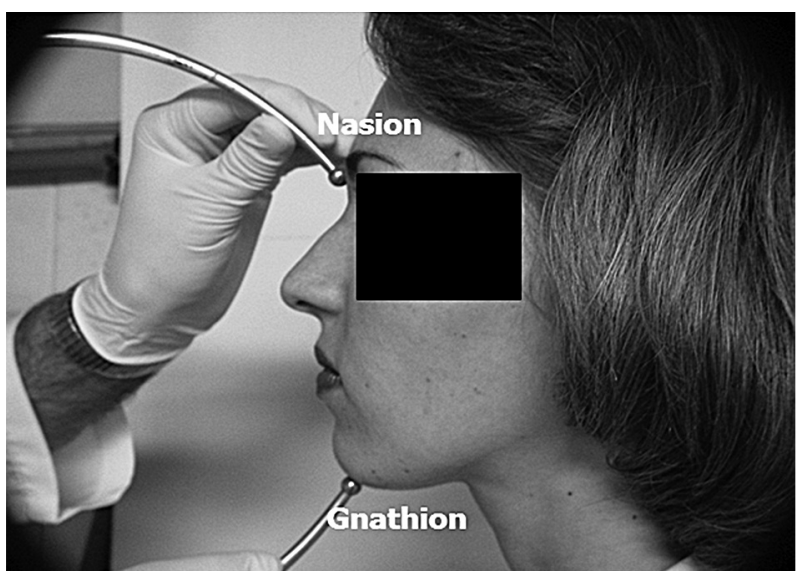

Figure 2. Total face height (nasion-gnathion: n-gn). 


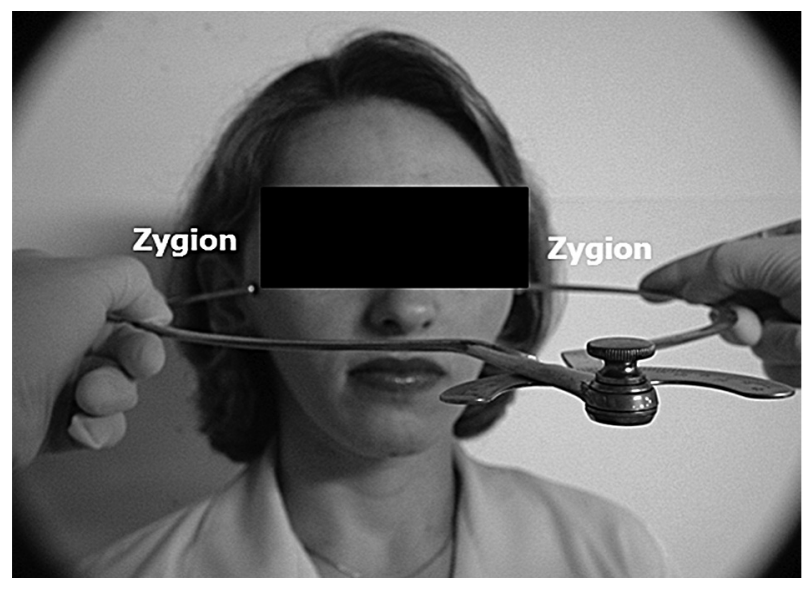

Figure 3. Face width (zygion-zygion: zy-zy).

During face measurement, the patients stood in erect posture, barefoot, heel-to-heel, with their arms hanging alongside their body. Their head was kept in a natural position, based on the Frankfurt plane, with sealed lips and teeth in an occlusal position. ${ }^{24}$

The Facial Brugsch Index formula $(\mathrm{FI}=[\mathrm{n}$-gn] $\mathrm{x} 100 /$ [zy-zy] $)$ was used to classify the facial types as follows:

FI lower than or equal to $84.9=$ euryprosopic;

FI equals 85.0 to $89.9=$ mesoprosopic; and

FI higher than or equal to $90.0=$ leptoprosopic. ${ }^{26}$

\section{Statistical analysis}

Quantitative variables were represented by mean values and standard deviation (SD), whereas qualitative variables, by absolute and relative frequency (\%). Data related to the three facial types assessed were submitted to Chi-square. Age distribution according to facial types was submitted to Levene and Shapiro-Wilk tests to verify variance homogeneity and data distribution, respectively. Data regarding facial types and age were submitted to ANOVA and Tukey's test, using BioEstat 5.0 (Mamiraua, Belém, Brazil) and Prism 5.0 (GraphPad Software Inc., San Diego, USA), both at a significance level of $5 \%$.

A power calculation was performed a posteriori by using the Chi-square value obtained, the effect size observed, and considering a 2-tail test, with a 5\% significance level. The resulting test power was $74.5 \%$.

\section{Results}

Figure 4 shows the FI values according to each facial type for all the individuals, 27 of whom revealed euryprosopic (48\%), 18 mesoprosopic (32\%), and 11 leptoprosopic (20\%) facial types. A statistically significant difference (Chi-Square, $p=0.032$ ) was found among the facial types, in that the leptoprosopic type showed the lowest values for muscle TMD.

The age of patients with a leptoprosopic facial type was found to be significantly lower than that of those having either of the two other facial types $(p<0.05)$, both of which had no statistical difference (Figure 5).

Table shows a greater $(p=0.0007)$ number of muscle TMD cases in the 20-to-39-year-old subjects than other the age segments.

\section{Discussion}

Of the approaches used to study the growth and characteristics of the head, the anthropometric technique is more effective in describing the craniofacial morphology of humans. ${ }^{22}$ In the present study, an instrument-based technique was preferred from among the many existing anthropometric techniques, since the direct quantitative measurement of soft-tissues using instruments (anthropometer) is non-invasive, enables access to areas covered by hair and avoids distortion caused by other indirect anthropometric techniques, such as photography. ${ }^{27,28}$

In the present study, patients were selected based on the Research Diagnostic Criteria (RDC/TMD), ${ }^{23}$ according to which all patients had to present with muscular TMD and not articular TMD, for homogeneity purposes. A higher prevalence of muscular rather than articular TMD has been reported. ${ }^{29,30,31}$

Other epidemiological aspects, such as gender and age, were considered. A higher prevalence of TMD in women, age 20 to 39 years, has been reported in several epidemiological studies. ${ }^{21,29,32,33}$ The results obtained in our study showed a higher prevalence of TMD in women, especially age 20-29 years, similar to the findings reported in other studies in the literature. ${ }^{16,21,30}$

No consensus was found in the literature toward the relationship between TMD and facial types. Stringert and Worms ${ }^{34}$ reported a higher prevalence of individuals with a hyperdivergent face, and a lower prevalence of those with a hypodivergent face, associated with internal derangement of the TMJ. This is in disaccord with the findings of the present study, which showed a higher prevalence of 


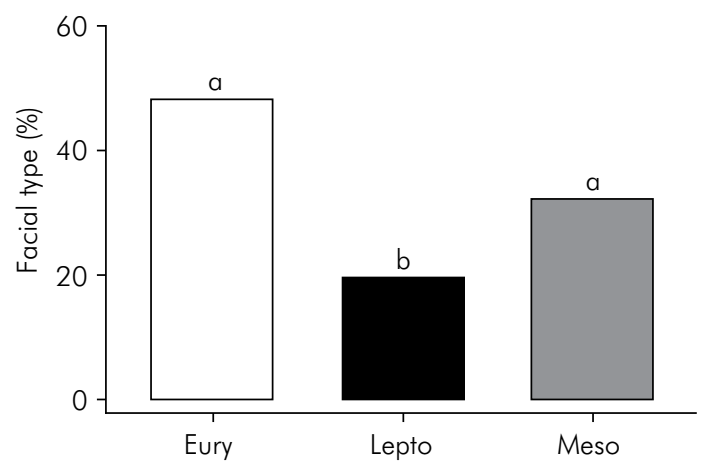

Figure 4. Distribution among facial types. Different lowercase letters show a statistical difference between facial types $(p=0.032)$.

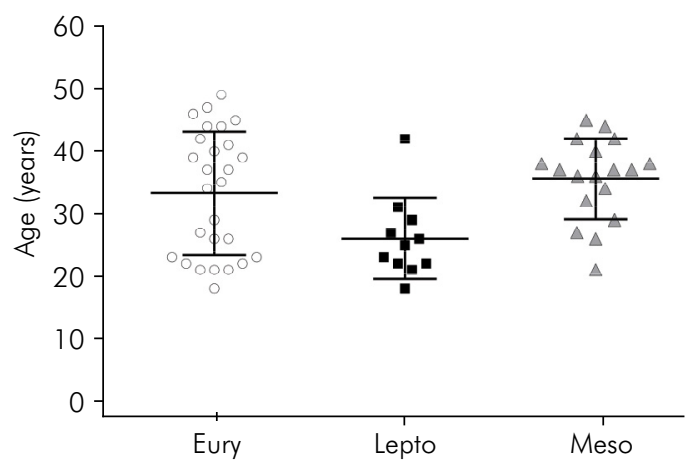

Figure 5. Means and standard error of TMD patient ages, according to facial type. Different letters indicate a statistical difference (ANOVA, Tukey's test, $\mathrm{p}<0.05$ ).

Table. Representation of ages ranging from 18 to 49 years, and euryprosopic (eury), mesoprosopic (meso) and leptoprosopic (lepto) facial types. Mean of 32.6 years, SD $=8.8$ years.

\begin{tabular}{lcccc}
\hline Facial Type/ Age & Eury & Meso & Lepto & Total (\%) \\
\hline$<20$ & 1 & 0 & 1 & $2(4 \%)$ \\
$20-29$ & 11 & 4 & 8 & $23(40 \%)$ \\
$30-39$ & 6 & 10 & 1 & $17(29 \%)$ \\
$40-49$ & 9 & 4 & 1 & $14(27 \%)$ \\
Total (\%) & $27(48 \%)$ & $18(32 \%)$ & $11(20 \%)$ & $56(100 \%)$ \\
\hline
\end{tabular}

\section{References}

1. Fields HW, Proffit WR, Nixon WL, Phillips C. Stanek E. Facial pattern differences in long-faced children and adults. Am J Orthod. 1984 Mar;85(3):217-23.

2. Di Dio LJ. The importance of anatomy. Ann Anat. 1999 Sep;181(5):455-65. individuals with a euryprosopic facial type, a result similar to that reported by Jefferson, ${ }^{5}$ assuming that individuals with skeletal deep bite could be more susceptible to TMD.

Several studies, investigating dolichofacial (long face) patterns on radiographic images, have correlated occlusal instability and low activity of the mandibular elevator muscles with the long facial type, factors that make the muscle more sensitive to masticatory forces. ${ }^{8,9}$ The present study showed a lower prevalence of muscle TMD in women with a leptoprosopic facial type.

Although the sample size in the present study was enough to validate the results, as observed by the power calculated, a greater number of samples in a broader population could provide sounder results in future studies. In addition, many other factors, such as environmental conditions, socioeconomic stratum, race, ethnicity, breathing pattern and nutritional habits, are likely to contribute to facial shape, and, consequently, influence the results, as previously observed. In addition, some landmark variations could have influenced the measurements. ${ }^{28}$

Most of the previous studies have been performed using lateral radiographic cephalometry. The latest anthropometric measurements were conducted between 1970 and 2000. Further studies are needed to compare anthropometric and radiographic cephalometry in the Brazilian population.

\section{Conclusion}

Women, age 20 to 39 years old, with muscular TMD, were more likely to be euryprosopic than other facial types. However, further studies are needed to investigate this hypothesis.

\section{Acknowledgements}

The authors wish to thank Jorge Valério for his assistance in the English language.
3. Ingervall B, Thilander B. Relation between facial morphology and activity of the masticatory muscles. J Oral Rehabil. 1974 Apr;1(2):131-47.

4. Proffit WR, Fields HW, Nixon WL. Occlusal forces in normal-and long-face adults. J Dent Res. 1983 May;62(5):566-70. 
5. Jefferson Y. TMD assessment using the Sassouni analysis 1. J Gen Orthod. 1991 Mar;2(1):11-5.

6. Monje F, Delgado E, Navarro MJ, Miralles C, Alonso del Hoyo JR. Changes in the temporomandibular joint caused by the vertical facial pattern. Study on an experimental model. J Craniomaxillofac Surg. 1994 Dec;22(6):361-70.

7. Nebbe B, Major PW, Prasad NG, Grace M, Kamelchuk LS. TMJ internal derangement and adolescent craniofacial morphology: a pilot study. Angle Orthod. 1997;67(6):407-14.

8. Bakke M, Michler L. Temporalis and masseter muscle activity in patients with anterior open bite and craniomandibular disorders. Scand J Dent Res.1991 Jun;99(3):219-28.

9. Sonnesen L, Bakke M, Solow B. Temporomandibular disorders in relation to craniofacial dimensions, head posture and bite force in children selected for orthodontic treatment. Eur J Orthod. 2001 Apr;23(2):179-92.

10. McLaughlin RP. Malocclusion and the temporomandibular joint - an historical perspective. Angle Orthod. 1988 Apr;58(2):185-91.

11. Jefferson Y. TMD assessment using the Sassouni analysis 2. J Gen Orthod. 1991 Jun;2(2):20-2.

12. Dao TT, LeResche L. Gender differences in pain. J Orofac Pain. 2000 Summer;14(3):169-84; discussion 184-95.

13. Cooper BC, Kleinberg I. Examination of a large patient population for the presence of symptoms and signs of temporomandibular disorders. Cranio. 2007 Apr;25(2):114-26.

14. Koidis PT, Zarifi A, Grigoriadou E, Garefis P. Effect of age and sex on craniomandibular disorders. J Prosthet Dent. 1993 Jan;69(1):93-101.

15. Carlsson GE, LeResche L. Epidemiology of temporomandibular disorders. In: Sessle BJ, Bryant PS, Dionne RA, editors. Temporomandibular disorder and related pain conditions. Seattle: IASP Press; 1995. p. 211-26.

16. LeResche L, Saunders K, Von Korff MR, Barlow W, DworkinSF. Use of exogenous hormones and risck of temporomandibular disorder pain. Pain. 1997 Jan;69(1-2):153-60.

17. Glaros AG, Baharloo L, Glass EG. Effect of parafunctional clenching and estrogen on temporomandibular disorder pain. Cranio. 1998 Apr;16(2):78-83.

18. Phillips JM, Gatchel RJ, Wesley AL, Ellis E 3rd. Clinical implications of sex in acute temporomandibular disorders. J Am Dent Assoc. 2001 Jan;132(1):49-57.

19. Macfarlane TV, Blinkhorn AS, Davies RM, Kincey J, Worthington HV. Association between female hormonal factors and oro-facial pain: study in the community. Pain. 2002 May;97(1-2):5-10.

20. Meisler JG. Chronic pain conditions in women. J Womens Health. 1999 Apr;8(3):313-20.
21. Kuttila M, Niemi PM, Kuttila S, Alanen P, Le Bell Y. TMD treatment need in relation to age, gender, stress, and diagnostic subgroup. J Orofac Pain. 1998 Winter;12(1):67-74.

22. Guyot L, Richard O, Philip N, Dutour O. Craniofacial anthropometric patterns in genetic facial dysmorphism: methodology and applications. Rev Stomatol Chir Maxillofac. 2002 Apr;103(2):114-9.

23. Dworkin SF, LeResche L. Research diagnostic criteria for temporomandibular disorders: review, criteria, examinations and specifications, critique. J Craniomandib Disord. 1992 Fall;6(4):301-55.

24. Farkas LG, Posnick JC, Hreczko TM. Growth patterns of the face: a morphometric study. Cleft Palate Craniofac J. 1992 Jul;29(4):308-15.

25. Allanson JE. Objective techniques for craniofacial assessment: what are the choices? Am J Med Genet. 1997 May;70(1):1-5.

26. Farkas LG, Munro IR, editors. Anthropometric facial proportions in medicine. Springfield: Charles C Thomas; 1987.

27. Farkas LG, Deutsch CK. Anthropometric determination of craniofacial morphology. Am J Med Genet. 1996 Oct;65(1):1-4.

28. Torres-Restrepo AM, Quintero-Monsalve AM, Giraldo-Mira JF, Rueda ZV, Vélez Trujillo N, Botero-Mariaca P. Agreement between cranial and facial classification through clinical observation and anthropometric measurement among Envigado school children. BMC Oral Health. 2014 May;14:50.

29. Espósito CJ, Panucci PJ, Farman AG. Associations in 425 patients having temporomandibular disorders. J Ky Med Assoc. 2000 May;98(5):213-5.

30. Vollaro S, Michelotti A, Cimino R, Farella M, Martina R. Epidemiologic study of patients with craniomandibular disorders. Report of data and clinical findings. Minerva Stomatol. 2001 Jan-Feb;50(1-2):9-14.

31. Huang GJ, LeResche L, Critchlow CW, Martin MD, Drangsholt MT. Risk factors for diagnostic subgroups of painful temporomandibular disorders (TMD). J Dent Res 2002 Apr;81(4):284-8.

32. Magnusson T, Egermak I, Carlsson GE. A longitudinal epidemiologic study of signs and symptoms of temporomandibular disorders from 15 to 35 years of age. J Orofac Pain. 2000 Fall;14(4):310-9.

33. Johansson A, Unell L, Carlsson GE, Soderfeldt B, Halling A. Gender difference in symptoms related to temporomandibular disorders in a population of 50-year-old subjects. J Orofac Pain. 2003 Winter;17(1):29-35.

34. Stringert HG, Worms FW. Variations in skeletal and dental patterns in patients with structural and functional alterations of the temporomandibular joint: A preliminary report. Am J Orthod. 1986 Apr;89(4):285-97. 